\title{
Immunization of rabbits with synthetic peptides derived from a highly conserved $\beta$-sheet epitope region underneath the receptor binding site of influenza $A$ virus
}

\author{
This article was published in the following Dove Press journal: \\ Biologics:Targets and Therapy \\ 4 November 2013 \\ Number of times this article has been viewed
}

\begin{abstract}
Shoji Ideno',3
Kaoru Sakai'

Mikihiro Yunoki ${ }^{2-4}$

Ritsuko Kubota-Koketsu ${ }^{3,5}$

Yuji Inoue ${ }^{3}$

Shota Nakamura ${ }^{6}$

Teruo Yasunaga ${ }^{6}$

Yoshinobu Okuno ${ }^{5}$

Kazuyoshi Ikuta ${ }^{3}$

'Infectious Pathogen Research Section, Central Research Laboratory, Research and Development Division, Japan Blood Products Organization,

Kobe, Japan; ${ }^{2}$ Research and

Development Promotion Section, Research and Development Division, Japan Blood Products Organization,

Tokyo, Japan; ${ }^{3}$ Department of Virology, Research Institute for Microbial Diseases, Osaka University, Suita, Osaka, Japan; ${ }^{4}$ Department of Veterinary Microbiology, School of Veterinary Medicine, Rakuno Gakuen University, Ebetsu, Hokkaido, Japan; ${ }^{5}$ Kanonji Institute, The Research Foundation for Microbial Diseases of Osaka University, Kanonji, Kagawa, Japan; ${ }^{6}$ Department of Genome Informatics, Genome Information Research Center, Research Institute for Microbial Diseases, Osaka University, Suita, Osaka, Japan
\end{abstract}

Correspondence: Shoji Ideno

Central Research Laboratory, Japan Blood Products Organization, 8F Kobe KIMEC

Center Building 1-5-2, Minatojimaminamimach, Chuo-ku, Kobe city, Hyogo 650-0047, Japan

Email ideno-shouji@jbpo.or.jp
Background: There is increasing concern about the speed with which health care providers can administer prophylaxis and treatment in an influenza pandemic. Generally, it takes several months to manufacture an influenza vaccine by propagation of the virus in chicken eggs or cultured cells. Newer, faster protocols for the production of vaccines that induce broad-spectrum immunity are therefore highly desirable. We previously developed human monoclonal antibody B-1 that shows broadly neutralizing activity against influenza A virus H3N2. B-1 recognizes an epitope region that includes an antiparallel $\beta$-sheet structure underneath the receptor binding site of influenza hemagglutinin (HA). In this study, the efficacy of a synthetic peptide vaccine derived from this epitope region against influenza A was evaluated.

Materials and methods: Two peptides were synthesized, the upper and lower peptides. These peptides comprise amino acid residues 167-187 and 225-241, respectively, of the B-1 epitope region of HA, which is involved in forming the $\beta$-sheet structure. Both peptides were then coupled to keyhole limpet hemocyanin, and the peptides, alone or in combination, were used to immunize rabbits. The resulting antibody responses were examined by enzyme-linked immunosorbent assay. The upper peptide, but not the lower peptide, elicited antibodies that were reactive to HA. Interestingly, the use of both peptides together could elicit antibodies with a higher reactivity to HA than either peptide alone. The antibodies were found to react to $\mathrm{HA}$ at the N-terminus of the upper peptide, which is exposed at the surface of trimeric HA on influenza virions.

Discussion: The higher production of HA-reactive antibodies following immunization with both peptides suggests that the upper peptide forms the effective epitope structure in the binding state, and the lower peptide enhances the production of HA antibodies. This study could be the first step towards the development of pandemic viral vaccines that can be produced within short time periods.

Keywords: influenza A, hemagglutinin, epitope, synthetic peptide, rabbit

\section{Introduction}

Influenza is one of the major causes of morbidity and mortality around the world. Influenza A viruses cause influenza, not only in humans but also in birds and some mammals, and transmission from animals to humans may lead to human influenza pandemics. Frequent minor changes in the antigenic glycoproteins hemagglutinin (HA) and/or neuraminidase (NA) produce new virus strains, which may be responsible for widespread seasonal influenza epidemics. ${ }^{1}$ 
HA is the principal antigen for determining host specificity and inducing neutralizing antibodies. ${ }^{2}$ The swineorigin pandemic influenza A virus (H1N1) that emerged in 2009 was the same subtype as one of the seasonal influenza A viruses. Therefore, some memory immune cells were already present in the general human population, ${ }^{3}$ and a significant neutralizing activity against the H1N1 pandemic in 2009 was detected in human immunoglobulin (Ig)G preparations. ${ }^{4}$ The possible appearance of a new pandemic virus derived from the highly pathogenic avian influenza virus has recently become a major concern, and careful monitoring of the population is required. ${ }^{5}$

Currently, egg- and cell culture-based viral vaccines are available for influenza. The effectiveness of the vaccines is largely dependent on the accuracy of the predictions about the prevalence and spread of the circulating viral strains that are used to determine the vaccines' contents. The reliance on these predictions means that the vaccine manufacturing process is under a severe time constraint, because vaccines can be manufactured only after each year's predictions. ${ }^{1}$ Therefore, novel systems for the rapid and scalable production of vaccines against emerging viral strains are highly desirable,${ }^{6}$ and a number of potentially rapid methods of vaccine production based on synthetic peptides have been recently tested. ${ }^{7-9}$

In an earlier study, we described two human monoclonal antibodies, B-1 and D-1, which had the ability to neutralize a wide range of influenza $\mathrm{A}$ virus $\mathrm{H} 3 \mathrm{~N} 2$ strains. ${ }^{10}$ These antibodies were prepared using peripheral blood mononuclear cells from two influenza-vaccinated, healthy donors. ${ }^{10}$ Both of these monoclonal antibodies recognize a similar epitope region, which includes two highly conserved sequences that form an antiparallel $\beta$-sheet structure in the HA1 amino acid sequence. ${ }^{10,11}$ These two sequences - amino acid residues 167-187 and 225-241 (using H3 numbering) - are located underneath the receptor binding site of HA1, and are hereafter referred to as the upper and lower peptides, respectively. This highly conserved epitope may provide the basis for a peptide vaccine that can elicit antibodies that are broadly protective against the influenza virus, as described previously. ${ }^{1,12,13}$ In this study, we examined whether immunizing rabbits with the upper and/or lower peptides resulted in the production of antibodies that were reactive with HA.

\section{Materials and methods}

\section{Reagents}

An influenza HA split vaccine (BIKEN HA; the Research Foundation for Microbial Diseases of Osaka University, Kanonji, Japan) containing A/Brisbane/59/2007 (H1N1), A/
Uruguay/716/2007 (H3N2), B/Florida/4/2006, and each HA antigen was used. Peptides were synthesized by the Thermo Fisher Scientific (Rockford, IL, USA). The peptide sequences used in this study are shown in Figure 1. Recombinant HA from A/New York/55/2004 (H3N2) was purchased from Protein Science Corporation (Meriden, CT, USA). It was expressed using the baculovirus vector system and was purified to $>90 \%$ under conditions that preserved its biological activity and tertiary structure (based on a Certificate of Analysis from the Protein Science Corporation).

\section{Conjugation of peptides to keyhole limpet hemocyanin}

Ten milligrams of keyhole limpet hemocyanin (KLH) were dissolved in $2 \mathrm{~mL}$ of $0.1 \mathrm{M}$ of sodium phosphate buffer (pH 7.4) and mixed with $4.5 \mathrm{mg}$ of the relevant peptide dissolved in $900 \mu \mathrm{L}$ of the same buffer. After $0.3 \mathrm{~mL}$ of $0.25 \%$ glutaraldehyde solution was added, the mixture was gently mixed at room temperature overnight and then dialyzed against distilled water.

\section{Immunization of rabbits}

Immunization of the rabbits was carried out at Thermo Fisher Scientific. New Zealand White rabbits were immunized subcutaneously with peptides conjugated to KLH. There were two rabbits in each of three treatment groups, immunized with either: (1) the upper peptide alone (rabbits aU-1 and aU-2); (2) the lower peptide alone (rabbits aL-1 and aL-2); or 3) both the upper and lower peptides (rabbits $\mathrm{aU}+\mathrm{L}-1$ and $\mathrm{aU}+\mathrm{L}-2$ ). The upper and lower peptides were conjugated separately to KLH and then mixed together before immunization. For the primary immunization, $1 \mathrm{mg}$ of each peptide was administered with Freund's complete adjuvant. For booster immunizations, $0.5 \mathrm{mg}$ of each peptide was administered with Freund's incomplete adjuvant 1 month after the primary immunization and then once more 2 weeks after that. Blood was collected 1 week after the final immunization and antisera were prepared.

\section{Measurement of anti-epitope peptide binding activity by ELISA}

The peptide, biotinylated at the N- or C-terminal amino acid, was dissolved in SuperBlock T20 (Thermo Fisher Scientific) to a final concentration of $1 \mu \mathrm{g} / \mathrm{mL}$ and then immobilized onto the wells of a 96-well streptavidin precoated plate (Nunc A/S, Roskilde, Denmark) via biotin-streptavidin binding. After incubating for 30 minutes at room temperature, the enzyme-linked immunosorbent assay (ELISA) plates were 
A

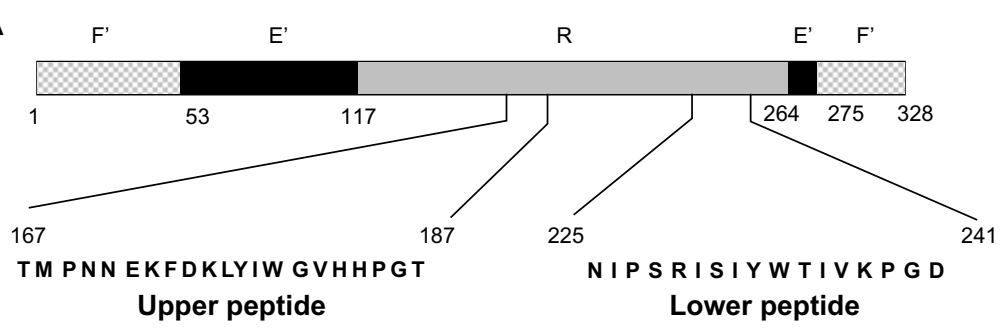

B

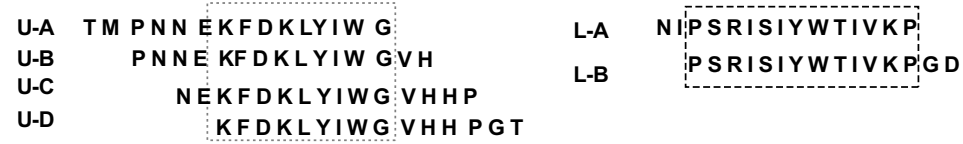

C

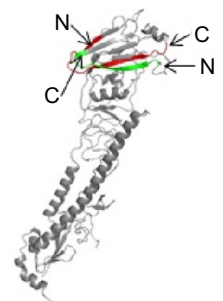

Monomer HA

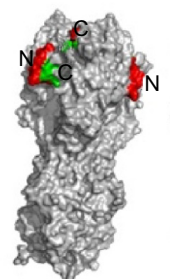

Front view of trimer HA
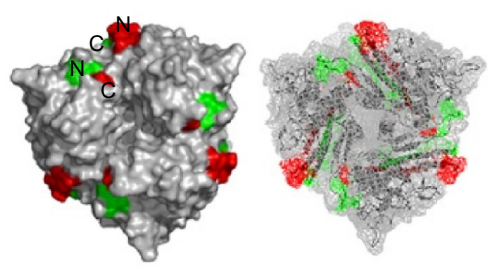

Top view of trimer HA

Figure I Schematic of the influenza HA epitope region and peptide sequences from the current study.

Notes: The position of the upper and lower peptides in the primary sequence of HAI and their amino acid sequences are indicated. F', E', and R (A). Overlapping I5-mer peptides derived from the upper (U-A, U-B, U-C, and U-D) and lower (L-A and L-B) regions that were used to examine antibody specificity (B). Image of the HA molecule showing the position of the upper (red) and lower (green) epitope peptide regions (C). The images were created by PyMol (DeLano Science) using the HA structure obtained from the Protein Data Bank. ${ }^{14}$ The monomer HA was created using accession number 2VIU, described by Fleury et al, and the trimer HA was created using accession number IHGI, described by Sauter et al. ${ }^{14}$ The upper and lower peptides form an antiparallel $\beta$-sheet structure. Large portions of the $\mathrm{N}$-terminus of the upper peptide and the $\mathrm{C}$-terminus of the lower peptide are exposed on the surface underneath the receptor binding site, and small portions of the $\mathrm{C}$-terminus of the upper peptide and the $\mathrm{N}$-terminus of the lower peptide are exposed on the surface near the receptor binding site.

Abbreviations: F', fusion peptide subdomain; E', vestigial enzyme subdomain; R, receptor binding subdomain; HA, influenza hemagglutinin; N, N-terminal portion of the peptide; C, C-terminal portion of the peptide.

flicked out and the wells were blocked with $3 \%$ skim milk in phosphate buffered saline (PBS) at room temperature for at least 1 hour. The antisera were diluted serially from $1: 1,000$ to $1: 125,000$ in PBS containing $3 \%$ skim milk. The wells were washed three times with distilled water and then incubated with the diluted antisera for 1.5 hours at room temperature. The wells were washed with PBS containing $0.05 \%$ Tween-20, and incubated with $50 \mu \mathrm{L}$ of peroxidaseconjugated antirabbit IgG (Beckman Coulter, Inc, Brea, CA, USA) diluted with SuperBlock T20 for 1 hour at room temperature. The wells were washed with PBS containing $0.05 \%$ Tween-20, then $100 \mu \mathrm{L}$ of substrate (Sumitomo Bakelite Co, Ltd, Tokyo, Japan) was added, and the plate was incubated for 20 minutes at room temperature. Stop solution (100 $\mu \mathrm{L} /$ well; Sumitomo Bakelite Co, Ltd) was added and the absorbance was measured at $490 \mathrm{~nm}$.

\section{Measurement of binding specificity of antipeptide antibodies by ELISA}

The influenza HA vaccine preparation was diluted 30 -fold with PBS. Overlapping 15-mer peptides were diluted to
$10 \mu \mathrm{g} / \mathrm{mL}$, and recombinant HA protein was diluted to $1 \mu \mathrm{g} / \mathrm{mL}$ with PBS. Fifty microliters of these antigens were added to wells of a 96-well Maxisorp microplate (Nunc A/S). Plates were incubated at $5^{\circ} \mathrm{C}$ overnight, and were then flicked out. Thereafter, the assay was carried out as for the measurement of anti-epitope peptide binding activity, as described above. The antisera were serially diluted from $1: 1,000$ to $1: 25,000$ for the HA binding assay, or they were diluted to 1:1,000 for the 15-mer peptide binding assay. The affinity-purified antibodies were diluted to $1 \mu \mathrm{g} / \mathrm{mL}$ in PBS containing 3\% skim milk.

\section{Affinity purification of antipeptide antibodies with peptide immobilized at the $\mathrm{N}$ - or $\mathrm{C}$-terminus}

The peptide, biotinylated at the $\mathrm{N}$ - or $\mathrm{C}$-terminal amino acid $(0.75 \mathrm{mg})$, was immobilized to $1 \mathrm{~mL}$ of streptavidin Sepharose (GE Healthcare UK Ltd, Little Chalfont, UK) via biotin-streptavidin binding according to the manufacturer's recommended protocol, then loaded onto a column, and washed with PBS. Rabbit antisera $(10 \mathrm{~mL})$ were applied 
to the columns, which were then washed with PBS. The bound antibodies were eluted with $0.1 \mathrm{M}$ glycine- $\mathrm{HCl}$ (pH 2.5) and immediately neutralized with a 1:10 volume of 1 M Tris- $\mathrm{HCl}$ ( $\mathrm{pH} 9.0$ ). Eluted antibodies were dialyzed against PBS.

\section{Evaluation of anti-HA binding activity by immunoblotting}

BIKEN HA vaccine antigens were subjected to sodium dodecyl sulfate polyacrylamide gel electrophoresis (Novex ${ }^{\circledR}$ NuPAGE ${ }^{\circledR}$ SDS-PAGE Gel System; Life Technologies) under reducing conditions alongside the SeeBlue Plus prestained standard (Life Technologies, Carlsbad, CA, USA). The HA vaccine antigens $(0.16 \mathrm{mg} / \mathrm{mL}$ to $0.18 \mathrm{mg} / \mathrm{mL})$ were mixed with lithium dodecyl sulfate sample buffer and reducing agent (Life Technologies) according to the manufacturer's instructions and boiled at $70^{\circ} \mathrm{C}$ for 10 minutes. Fractionated proteins were transferred to iBlot Regular Transfer Stacks (Life Technologies), blocked with 5\% skim milk in Trisbuffered saline containing $0.05 \%$ Tween-20, and probed with $1 \mu \mathrm{g} / \mathrm{mL}$ or $5 \mu \mathrm{g} / \mathrm{mL}$ of rabbit IgG purified from the antisera of rabbits immunized with the upper peptide, or both the upper and lower peptides using a protein $G$ Sepharose column (GE Healthcare Bio-Sciences AB). Binding ability was detected by chemiluminescence following incubation with a peroxidase-conjugated goat antirabbit IgG antibody (Beckman Coulter, Inc) and SuperSignal ${ }^{\mathrm{TM}}$ West Pico Chemiluminescent Substrate (Thermo Fisher Scientific) for 5 minutes. Membranes were exposed to X-ray film for 10 seconds and images were developed.

\section{Virus neutralization test}

The virus neutralization (VN) test was carried out as described previously. ${ }^{15}$ Briefly, the antisera were treated with a receptor-destroying enzyme, resulting in a tenfold reduction in concentration. The antisera were then mixed with 100 focus-forming units of influenza virus (final volume: $50 \mu \mathrm{L})$ and applied to Madin-Darby canine kidney cells in a 96-well microtiter plate. After culturing for 6 hours, the cells were fixed with ethanol and stained by the peroxidaseantiperoxidase staining method.

\section{Animal ethics}

After approval by the Ethics Committee at the Thermo Fisher Scientific, the immunization of rabbits was performed following the recommendations of the Institute of Laboratory Animal Resources, Commission on Life Sciences, National Research Council ${ }^{16}$ at Thermo Fisher Scientific.

\section{Results}

Rabbits were immunized with synthetic polypeptides corresponding to two highly conserved sequences spanning residues of 167-187 and 225-241 (the upper peptide and lower peptide, respectively) of the H3-type HA1, which includes the B-1 epitope region. Those two peptides form an antiparallel $\beta$-sheet structure in the HA molecule. According to a known crystal structure, a large portion of the N-terminus of the upper peptide (residues 167-175) and a small portion of the C-terminus of the lower peptide (residues 238-241) are observed to be exposed on the surface of the HA molecule underneath the receptor binding site, and small portions of the C-terminus of the upper peptide (residues 186-187) and the N-terminus of the lower peptide (residues 225-228) are exposed (Figure 1). Residues exposed to the surface were estimated from surface image of HA created by PyMol. Rabbits were immunized either with the upper peptide, the lower peptide, or a mixture of the two, and antisera were obtained. Using these antisera, the immune responses to the immunized peptide, the binding of elicited antibodies to HA, and the ability of the peptides to induce neutralizing antibodies to the influenza virus were investigated.

\section{Antibody responses to upper and lower peptides}

The antiserum from each immunized rabbit was examined for its reactivity against the same peptide used as the immunogen (Figure 2). The upper peptide showed strong reactivity with antisera from rabbits immunized with the upper peptide alone (aU) (Figure 2A and E) or with both the upper and lower peptides $(\mathrm{aU}+\mathrm{L})$ (Figure $2 \mathrm{~B}$ and $\mathrm{F}$ ). The binding of both the $\mathrm{aU}$ and the $\mathrm{aU}+\mathrm{L}$ antisera to the upper peptide immobilized at the N-terminus (Figure 2A and 2B) was stronger than to the upper peptide immobilized at the C-terminus (Figure $2 \mathrm{E}$ and $\mathrm{F}$ ). The reactivity of the $\mathrm{aU}+\mathrm{L}$ antisera to the peptide immobilized at the C-terminus (Figure 2F) was stronger than that of the aU antisera (Figure 2E). In comparison, the lower peptide induced only weak antibody responses (aL). The aL and $\mathrm{aU}+\mathrm{L}$ antisera showed low reactivity to the lower peptide immobilized at the N-terminus (Figure 2C and D) and no reactivity to the lower peptide immobilized at the C-terminus (Figure $2 \mathrm{G}$ and $\mathrm{H}$ ).

\section{Binding ability to HA}

Next, the reactivity of each serum and affinity purified antibody with the HA vaccine preparation (Figures 3 and 4) and with recombinant HA (Figure 5) were examined by ELISA. The antisera from both $\mathrm{aU}+\mathrm{L}$ rabbits showed strong antibody 

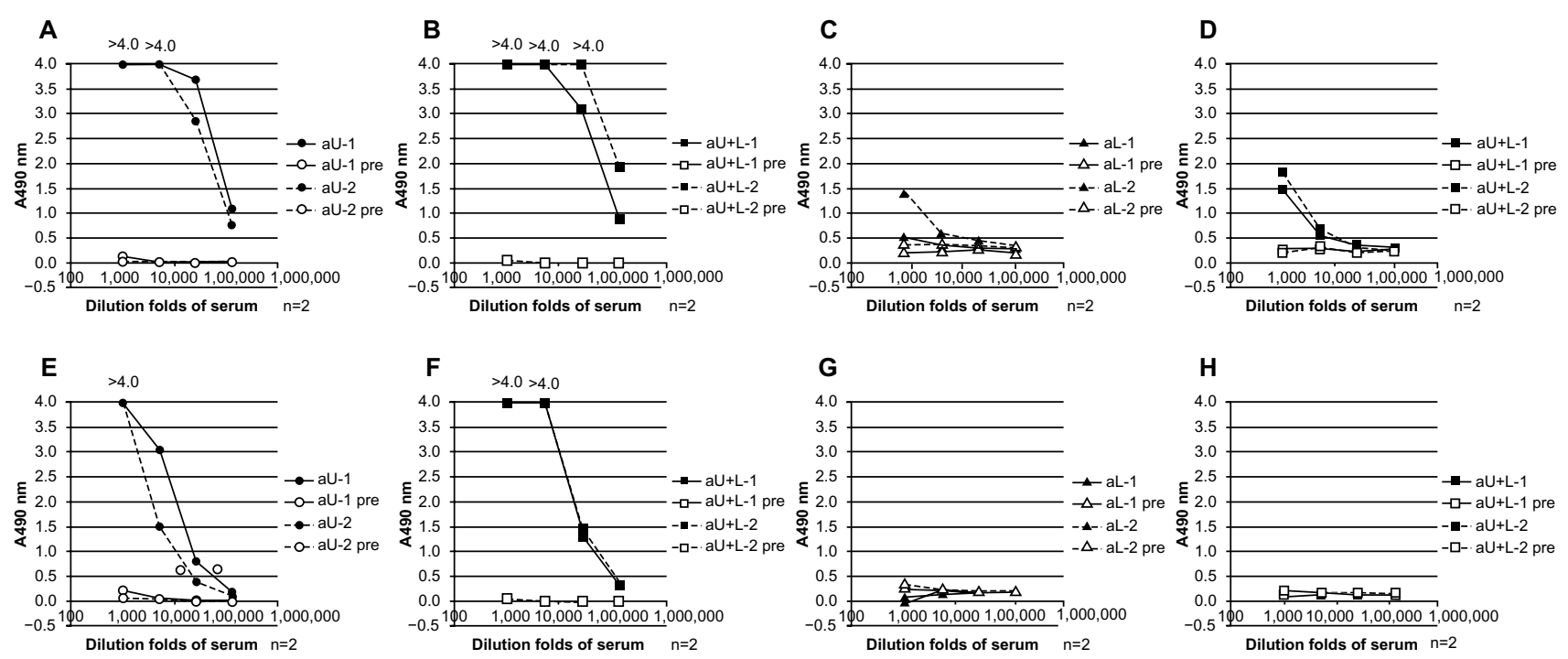

Figure 2 Binding activity of different rabbit antisera to epitope peptides, as determined by ELISA.

Notes: N-terminally biotinylated upper peptide ( $\mathbf{A}$ and $\mathbf{B}) ; \mathrm{N}$-terminally biotinylated lower peptide (C and $\mathbf{D})$; C-terminally biotinylated upper peptide $(\mathbf{E}$ and $\mathbf{F})$; and C-terminally biotinylated lower peptide $(\mathbf{G}$ and $\mathbf{H})$ were immobilized via biotin-streptavidin binding onto an ELISA plate that was precoated with streptavidin. The antisera were serially diluted from I:I,000 to I:I25,000. Rabbits immunized are designated as aU-I, aU-2, aL-I, aL-2, aU+L-I, and aU+L-2. Individual rabbits are indicated by “-I" and "-2." Experiments were carried out in duplicate, and the results are presented as means.

Abbreviations: $\mathrm{aU}$, rabbit immunized with upper peptide alone; pre, serum harvested from each rabbit prior to immunization; $\mathrm{n}$, number; $\mathrm{aU}+\mathrm{L}$, rabbit immunized with both the upper and lower peptides; aL, rabbit immunized with lower peptide alone; ELISA, enzyme-linked immunosorbent assay.

A

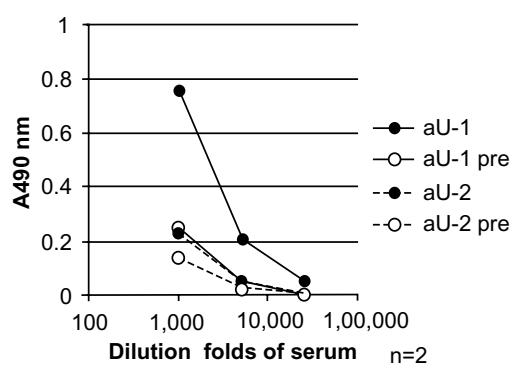

B

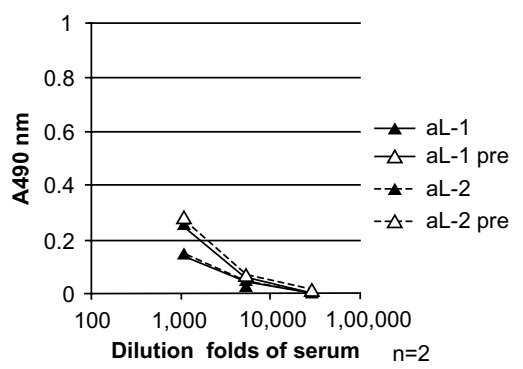

C

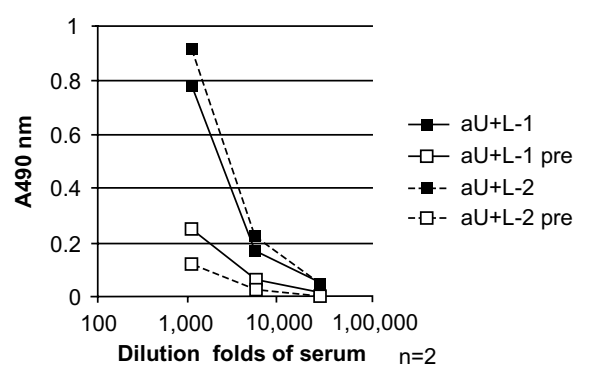

D

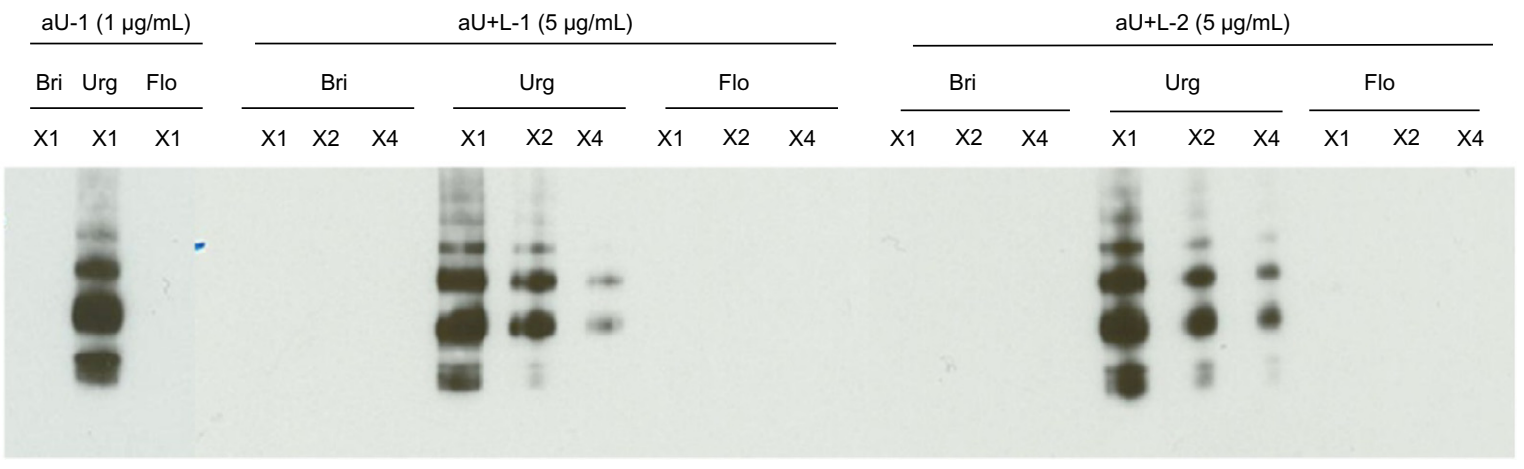

Figure 3 Binding ability of different rabbit antisera to HA, determined by ELISA and immunoblotting.

Notes: The HA vaccine preparation was used as coating antigen for an ELISA. The rabbit antisera were diluted serially from I:I,000 to I:25,000. Experiments were carried out in duplicate and results are presented as means (A, B, and C). For immunoblotting, different influenza HA vaccine antigens were subjected to SDS-PAGE, and immunoglobulin G purified with Protein-G® Sepharose (GE Healthcare UK Ltd, Little Chalfont, UK) from the antisera of rabbits aU-I, aU+L-I, and aU+L-2 was used as the probe at a concentration of I $\mu \mathrm{g} / \mathrm{mL}$ or $5 \mu \mathrm{g} / \mathrm{mL}$. Individual rabbits are indicated by "- 1 " and " -2 ." The designations " $\times 1$, , " $\times 2$," and " $\times 4$ " indicate that samples were loaded onto the gel at a one-, two-, or four-fold dilution.

Abbreviations: $\mathrm{n}$, number; aU, rabbit immunized with upper peptide alone; pre, serum harvested from each rabbit prior to immunization; aL, rabbit immunized with lower peptide alone; $\mathrm{aU}+\mathrm{L}$, rabbit immunized with both the upper and lower peptides; Bri, influenza hemagglutinin vaccine antigen derived from $\mathrm{A} / \mathrm{Brisbane} / 59 / 2007$ (HINI); Urg, influenza hemagglutinin vaccine antigen derived from A/Uruguay/7/6/2007 (H3N2); Flo, influenza hemagglutinin vaccine antigen derived from B/Florida/4/2006; HA, influenza hemagglutinin; ELISA, enzyme-linked immunosorbent assay; SDS-PAGE, sodium dodecyl sulfate polyacrylamide gel electrophoresis. 
responses with the HA vaccine and recombinant HA. A similarly strong antibody response to the HA vaccine was detected in antiserum from one aU rabbit. Both antisera from the aU rabbits showed a weak binding ability to recombinant HA compared with the antisera from the $\mathrm{aU}+\mathrm{L}$ rabbits. In the $\mathrm{aL}$ rabbits, no clear antibody responses to the $\mathrm{HA}$ vaccine or the recombinant HA were detected (Figures $3 \mathrm{~A}-\mathrm{C}$ and $5 \mathrm{~A}$ ).

The ability of the total IgG generated in immunized rabbits to bind the HA vaccine was further investigated by immunoblotting (Figure 3D). IgG that was purified with Protein G Sepharose ${ }^{\circledR}$ (GE Healthcare UK Ltd) from antiHA ELISA-positive sera (ie, from rabbits aU-1, aU+L-1, and $\mathrm{aU}+\mathrm{L}-2$ in Figure $3 \mathrm{~A}$ and $\mathrm{C}$ ) showed clear reactivity to HA vaccine antigens derived from the $\mathrm{H} 3 \mathrm{~N} 2$ strain, but did not react to the other HA serotypes tested. $\mathrm{IgG}$ in antiserum from rabbit aL-1, which showed faint binding to the HA vaccine by ELISA, did not show any reactivity to HA antigens by immunoblotting, even at an increased concentration $(10 \mu \mathrm{g} /$ $\mathrm{mL}$ ) (data not shown).

The ability of affinity-purified antipeptide antibodies recognizing the $\mathrm{N}$-terminal or $\mathrm{C}$-terminal region of the upper peptide (produced by affinity-purifying antisera with upper peptides immobilized to Sepharose at the C-or N-terminus) to bind to the HA vaccine (Figure 4A and B) and recombinant HA (Figure 5B) was also examined. There was no apparent difference in the reactivity of HA vaccine with the antibodies recognizing the $\mathrm{N}$-terminal region of the upper peptide (upper-N) in aU or aU+L rabbits (Figure 4B); however, the antibody recognizing the $\mathrm{C}$-terminal region of the upper peptide (upper-C) in one aU+L rabbit reacted more strongly to the HA vaccine than the other antibodies (Figure 4A). Antibodies recognizing upper-N from aU and $\mathrm{aU}+\mathrm{L}$ rabbits showed a greater reactivity to the HA vaccine and recombinant
HA compared to those recognizing upper-C. However, antisera from aL-1, aU+L-1, and aU+L-2 rabbits showed weak reactivity to the lower peptide immobilized at $\mathrm{N}$-terminus (Figure 2C and D), the antibodies from the same rabbits that were affinity-purified with the lower peptide immobilized at the N-terminus showed no reactivity by HA vaccine ELISA (Figure 4C). While antibodies recognizing upper-N and upper-C from both $\mathrm{aU}+\mathrm{L}$ rabbits reacted to recombinant $\mathrm{HA}$ definitely, antibodies recognizing upper- $\mathrm{N}$ from one aU rabbit reacted to it clearly, and the other one showed faint reactivity (Figure 5B).

\section{Specificity of antipeptide responses}

The antibody-binding specificities of antisera from the $\mathrm{aU}, \mathrm{aL}$, and $\mathrm{aU}+\mathrm{L}$ rabbits were examined by ELISA on plates precoated with 15-mer peptides within the upper and lower peptide regions (U-A to U-D; L-A, and L-B) (Figures $1 \mathrm{~B}$ and 6). Antisera from $\mathrm{aU}$ and $\mathrm{aU}+\mathrm{L}$ rabbits reacted strongly to the C-terminus of the upper peptide (U-D; amino acid residues 173-187 using H3 numbering). The antisera from aU+L rabbits also showed some reactivity to 15-mer peptides from the N-terminus of the upper peptide (U-A and U-B), whereas antisera from aU rabbits showed a faint or no reactivity to those peptides. The antisera from both $\mathrm{aU}+\mathrm{L}$ rabbits and one aL rabbit reacted faintly to $15-\mathrm{mer}$ peptides from the C-terminus (L-B) of the lower peptide.

\section{VN test}

Antisera treated with a receptor-destroying enzyme were tested for neutralization activity against influenza virus A/ Hiroshima/52/2005 (H3N2). Since the nonspecific neutralizing activity of sera obtained prior to immunization was strong, it was difficult to quantitatively evaluate the effect
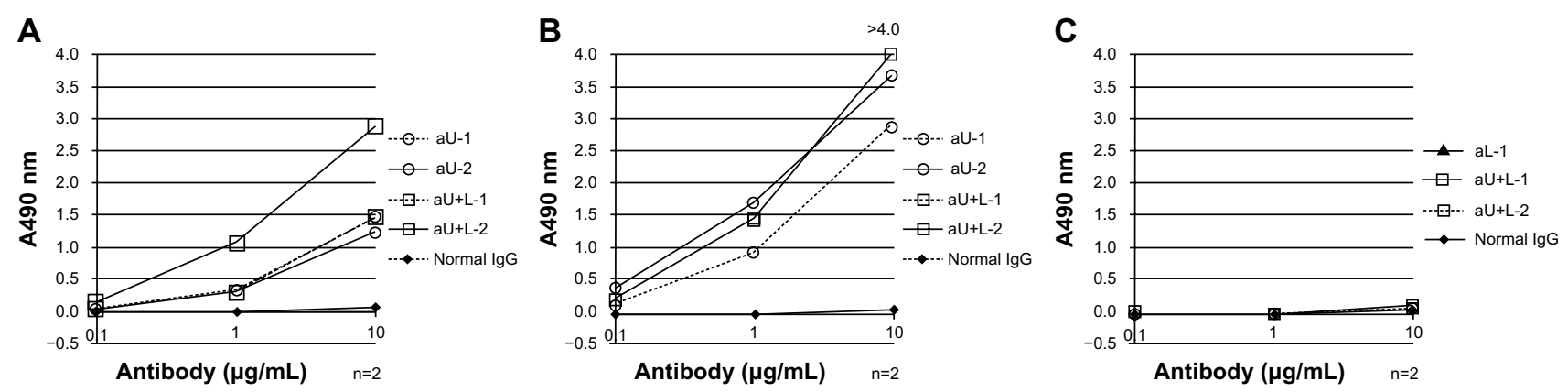

Figure 4 Binding abilities of antibodies affinity-purified with peptides to the HA vaccine, as determined by ELISA.

Notes: Antipeptide antibodies were purified by affinity binding with upper peptide immobilized on Sepharose via its $\mathrm{N}$-terminus (A) or C-terminus (B), or with lower peptide immobilized on Sepharose via its N-terminus (C). Antibodies were diluted from $10 \mu \mathrm{g} / \mathrm{mL}$ to $0.1 \mu \mathrm{g} / \mathrm{mL}$. Individual rabbits are indicated by "-I" and "-2." Experiments were carried out in duplicate and results are presented as means. Normal IgG was purified from commercial normal rabbit serum (CEDARLANE, Burlington, ON, Canada) with Protein G Sepharose ${ }^{\circledast}$ (GE Healthcare UK Ltd, Little Chalfont, UK).

Abbreviations: $\mathrm{aU}$, rabbit immunized with upper peptide alone; $\mathrm{aU}+\mathrm{L}$, rabbit immunized with both the upper and lower peptides; IgG, immunoglobulin $\mathrm{G}$; $\mathrm{n}$, number; aL, rabbit immunized with lower peptide alone; HA, influenza hemagglutinin; ELISA, enzyme-linked immunosorbent assay. 
of immunization on viral neutralization activity. Certainly, with our present protocol using rabbit sera, no discernible difference between antisera and preimmunization sera was observed (data not shown).

\section{Discussion}

The upper peptide derived from the $\beta$-sheet structure underneath the HA1 receptor binding site of the influenza A virus H3N2 was highly immunogenic and resulted in the production of antibodies that reacted to HA; conversely, the lower peptide, which was derived from the same structure, was not immunogenic. However, the antibody response elicited by immunization with a mixture of upper and lower peptides was much stronger than that with the upper peptide alone.

As shown in Figure 1C, a large part of the N-terminus of the upper peptide is exposed on the surface of HA trimers on virions, so it was hypothesized that the N-terminus of the upper peptide would induce higher reactivity to HA. In fact, antibodies specific to upper-N (ie, antibodies that were affinity-purified with upper peptide immobilized at the C-terminus) bound more strongly to the HA vaccine and to recombinant $\mathrm{HA}$ in antisera from $\mathrm{aU}$ and $\mathrm{aU}+\mathrm{L}$ rabbits (Figures 4 and 5B). Furthermore, the antibody in the antisera of aU-2 rabbits reacted strongly to the U-D peptide, which corresponds to the C-terminus of the upper peptide, but did not react to HA (Figures 3A, 5A and 6A). This suggests that the two $\mathrm{C}$-terminal amino acids of the upper peptide do not contribute to its ability to bind to HA. When the reactivity of different antisera to the N-terminus of the upper peptide was examined using the upper peptide immobilized at the $\mathrm{C}$-terminus, the antibodies from aU+L rabbits reacted more strongly than antibodies from aU rabbits (Figure 2E and F). The higher reactivity of antibodies from aU+L rabbits to the N-terminus of the upper peptide was further confirmed by ELISA using 15-mer peptides (Figure 6).

One possible explanation for the ability of immunization with both the upper and lower peptides to produce more HAreactive antibodies than immunization with the upper peptide alone may be an effect of the lower peptide on the conformation of the epitope region, particularly at the N-terminus of the upper peptide. As shown in Figures 3 and 5A, there was a strong antibody response in $\mathrm{aU}+\mathrm{L}$ rabbits to both the HA vaccine and recombinant $\mathrm{HA}$, whereas a response to recombinant $\mathrm{HA}$ in $\mathrm{aU}$ rabbits was weaker than that in $\mathrm{aU}+\mathrm{L}$ rabbits. The upper peptide sequence in the vaccine preparation and in recombinant HA were identical, except at residue 186 (Val and Gly) at the C-terminus (Figure 5C); this residue was not thought to contribute to the HA binding ability of the antibody.
These observations suggested that the difference of the antibody response between the $\mathrm{aU}$ and $\mathrm{aU}+\mathrm{L}$ rabbits resulted from the structure of the upper peptide $\mathrm{N}$-terminal region. The affinity-purified antipeptide antibodies from aU+L rabbit antisera reacted better to recombinant HA than to antibodies from aU rabbit antisera (Figure $5 \mathrm{~B}$ ). This observation may reflect an induced fit between the conformation of the peptide and the antibody during the affinity purification step. The results obtained by ELISA using the HA vaccine as the antigen, and by
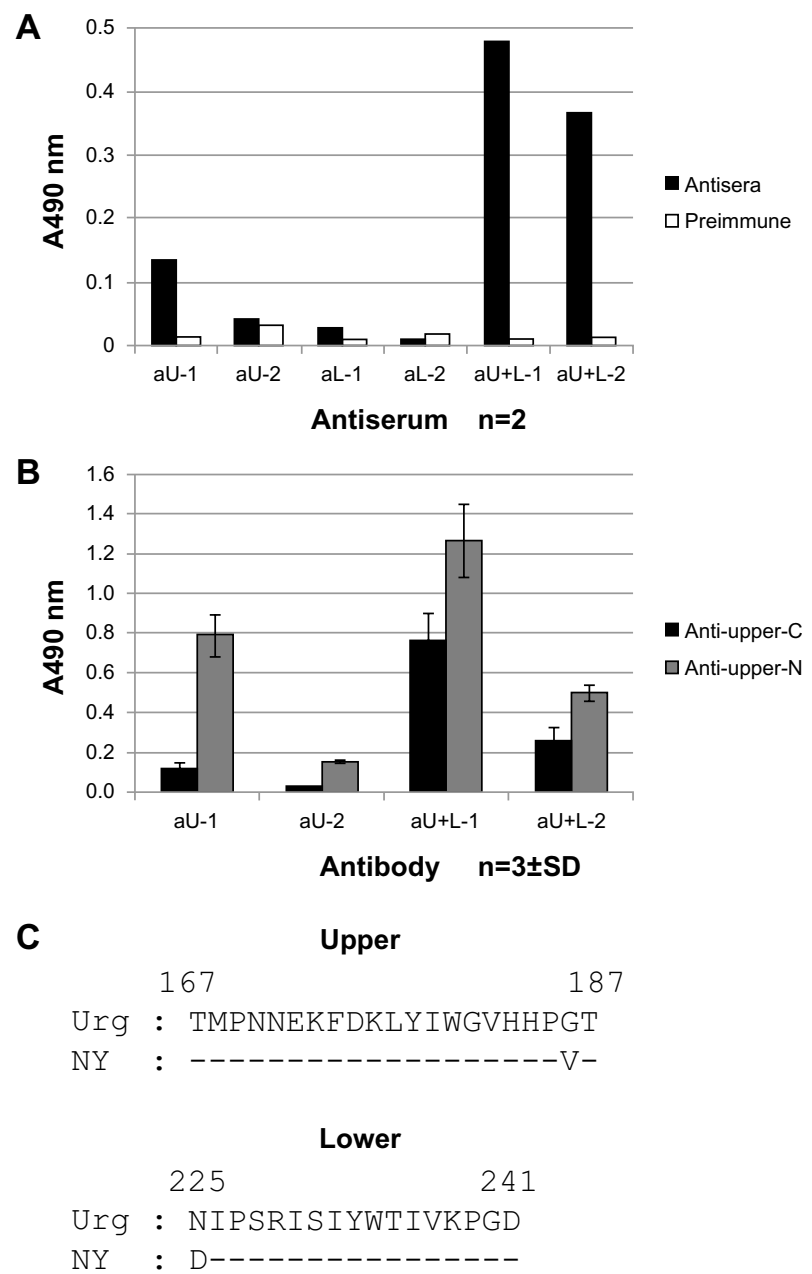

Figure $\mathbf{5}$ Binding affinities to recombinant HA, as determined by ELISA.

Notes: The ability of antisera (A) and affinity-purified antibodies (B) to bind recombinant $\mathrm{HA}$ was determined by ELISA. Antisera and affinity-purified antibodies were diluted to $\mathrm{I}: \mathrm{I}, 000$ and to $\mathrm{I} \mu \mathrm{g} / \mathrm{mL}$, respectively. Experiments were carried out in duplicate and the results are presented as means (A). Experiments were carried out in triplicate and results are presented as means \pm SD (B). Individual rabbits are indicated by "-I" and "-2." Anti-upper-N or anti-upper-C antibody was produced by affinity-purified antisera with the upper peptide immobilized at the C-terminus or at the $\mathrm{N}$-terminus, as described in Figure 4. Sequence comparison of the upper and lower peptide between NY, which was used as the source of recombinant HA, and Urg, which was used as the vaccine preparation (C).

Abbreviations: $\mathrm{a} \cup$, rabbit immunized with upper peptide alone; aL, rabbit immunized with lower peptide alone; $\mathrm{aU}+\mathrm{L}$, rabbit immunized with both the upper and lower peptides; n, number; Upper-C, C-terminal region of the upper peptide; Upper-N, N-terminal region of the upper peptide; SD, standard deviation; Urg, A/Uruguay/7/6/2007; NY, A/New York/55/2004; HA, influenza hemagglutinin; ELISA, enzyme-linked immunosorbent assay. 
A

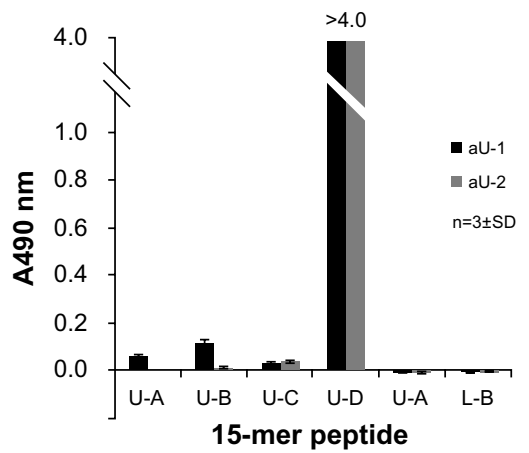

B

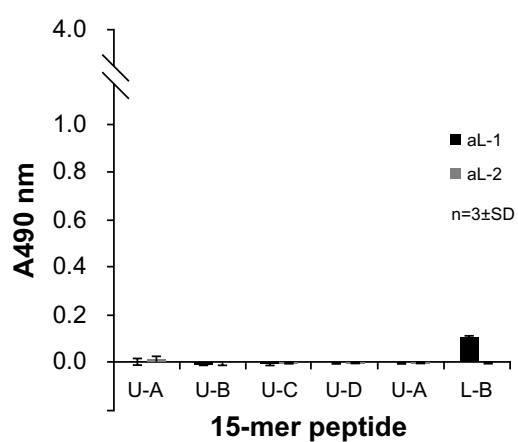

C

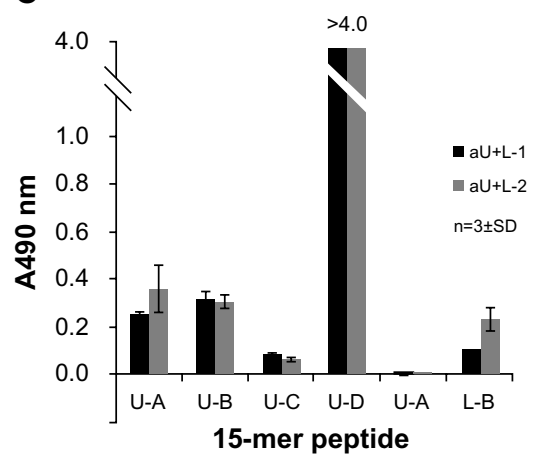

Figure 6 Binding activity of different rabbit antisera to 15-mer peptides within the upper and lower peptide regions of HA, as determined by ELISA. Notes: Antisera from immunized rabbits were diluted I:I,000 for use in the assay. The binding activity of antisera from aU rabbits $(\mathbf{A})$, aL rabbits (B), and aU+L rabbits (C) was measured by ELISA. "U-A," "U-B," "U-C," and "U-D" are I5-mer peptides located within the upper peptide region of HA, and "L-A" and "L-B" are I5-mer peptides within the lower peptide region of HA, as described in Figure I. Experiments were carried out in triplicate and results are presented as means \pm SD.

Abbreviations: $n$, number; SD, standard deviation; HA, influenza hemagglutinin; ELISA, enzyme-linked immunosorbent assay; aU, rabbit immunized with upper peptide alone; aL, rabbit immunized with lower peptide alone; $\mathrm{aU}+\mathrm{L}$, rabbit immunized with both the upper and lower peptides.

immunoblotting under reducing conditions, reflect the binding activity to denature HA rather than recombinant HA. These results suggest the possibility that an antibody recognizing the binding conformation of a protein could be induced by immunization with both the upper and lower peptides.

Generally, it seems difficult to raise antibodies with VN activity from synthetic peptide immunization, as shown in a study where goats were immunized with an epitope-derived synthetic peptide against a rabies virus. ${ }^{17}$ In this study, no neutralizing activity against the influenza virus could be detected in any of the immunized rabbits. This might indicate that the antigenic structures recognized by rabbit antipeptide antibodies in this study are different from those recognized by B-1, and further studies are necessary to identify peptidebased antigenic structures that can elicit strong neutralizing activity. In fact, an antibody derived from the antisera of an $\mathrm{aU}+\mathrm{L}$ rabbit, which was affinity-purified using upper peptide immobilized at the $\mathrm{C}$-terminus, was not competitive with the B-1 monoclonal antibody in an ELISA-based binding assay using the HA vaccine (data not shown).

In this study, we demonstrated that the immunization of rabbits with the upper peptide could induce the production of antibodies that bound to the native conformation of HA - an effect that was increased when rabbits were co-immunized with the lower peptide. This result is consistent with the observation that we have recently reported: a modified green fluorescent protein that residues derived from the upper region were introduced on its surface $\beta$-strand, which was aimed at reproducing the original secondary structure of the epitope, showed an anti-influenza-virus immunogenicity, and the lower-derived residues that were introduced additionally on its neighboring $\beta$-strand enhanced the immunogenicity. ${ }^{18}$ However, neutralization activity could not be detected in the antisera of immunized rabbits, and the strong neutralizing activity might not be induced by KLH peptide conjugate in this study. Further studies are necessary to evaluate the induction of neutralizing activity, because strong neutralizing activity was detected in the sera of nonimmunized rabbits. Even though, IgG was purified from the sera of nonimmunized rabbits with Protein-G Sepharose ${ }^{\circledR}$, nonspecific neutralizing factor could not be removed (data not shown). In vivo mouse infectious models of the influenza virus have been widely used, ${ }^{19}$ and a preliminary study in mice showed that nonspecific neutralization of the influenza virus in sera from nonimmunized animals was weak compared with that of nonimmunized rabbits. To induce the strong neutralizing activity, the antigenic conformation might be important, and further study to optimize the conformation is necessary. Moreover, synthetic peptide antigens might show protective activity in vivo by a mechanism other than the neutralizing antibody; this hypothesis is currently being investigated in mice.

\section{Acknowledgments}

We thank Professor Kenji Okonogi for the coordination of the collaborative project between Osaka University, Benesis Corporation, and the Research Foundation for Microbial Diseases of Osaka University.

\section{Author contributions}

SI, MY, and KI designed the experiments. SI, SN, and RKK performed the experiments. KS, YI, SN, TY, and YO contributed experimental reagents, materials, and/or analysis tools. SI, KS, and KI wrote the manuscript. MY, RKK, YI, and SN edited the manuscript. All authors critically revised the manuscript and approved the final version. 


\section{Disclosure}

This research was conducted as part of a collaborative project between Osaka University, the Benesis Corporation (at present, the Japan Blood Products Organization), and the Research Foundation for Microbial Diseases of Osaka University. The funders had no role in the study design, data collection or analysis, the decision to publish, or the preparation of the manuscript.

\section{References}

1. Ben-Yedidia T, Arnon R. Epitope-based vaccine against influenza. Expert Rev Vaccines. 2007;6(6):939-948.

2. Skehel JJ, Wiley DC. Receptor binding and membrane fusion in virus entry: the influenza hemagglutinin. Annu Rev Biochem. 2000;69: 531-569.

3. Greenbaum JA, Kotturi MF, Kim Y, et al. Pre-existing immunity against swine-origin $\mathrm{H} 1 \mathrm{~N} 1$ influenza viruses in the general human population. Proc Natl Acad Sci U S A. 2009;106(48):20365-20370.

4. Yunoki M, Kubota-Koketsu R, Urayama T, et al. Significant neutralizing activity of human immunoglobulin preparations against pandemic 2009 H1N1. Br J Haematol. 2010;148(6):953-955.

5. Amendola A, Ranghiero A, Zanetti A, Pariani E. Is avian influenza virus A(H5N1) a real threat to human health? J Prev Med Hyg. 2011;52(3): 107-110.

6. Tripp RA, Tompkins SM. Recombinant vaccines for influenza virus. Curr Opin Investig Drugs. 2008;9(8):836-845.

7. Vergara-Alert J, Argilaguet JM, Busquets N, et al. Conserved synthetic peptides from the hemagglutinin of influenza viruses induce broad humoral and T-cell responses in a pig model. PLoS One. 2012; 7(7):e40524.

8. Wang TT, Tan GS, Hai R, et al. Vaccination with a synthetic peptide from the influenza virus hemagglutinin provides protection against distinct viral subtypes. Proc Natl Acad Sci U S A. 2010;107(44): 18979-18984.
9. Babon JA, Cruz J, Ennis FA, Yin L, Terajima M. A human CD4+ T cell epitope in the influenza hemagglutinin is cross-reactive to influenza A virus subtypes and to influenza B virus. J Virol. 2012;86(17): 9233-9243.

10. Kubota-Koketsu R, Mizuta H, Oshita M, et al. Broad neutralizing human monoclonal antibodies against influenza virus from vaccinated healthy donors. Biochem Biophys Res Commun. 2009;387(1):180-185.

11. Yamashita A, Kawashita N, Kubota-Koketsu R, et al. Highly conserved sequences for human neutralization epitope on hemagglutinin of influenza A viruses H3N2, H1N1 and H5N1: Implication for human monoclonal antibody recognition. Biochem Biophys Res Commun. 2010;393(4):614-618.

12. Kaur K, Sullivan M, Wilson PC. Targeting B cell responses in universal influenza vaccine design. Trends Immunol. 2011;32(11):524-531.

13. Staneková Z, Varečková E. Conserved epitopes of influenza A virus inducing protective immunity and their prospects for universal vaccine development. Virol J. 2010;7:351.

14. RCSB Protein Data Bank [homepage on the Internet]. Available from: http://www.rcsb.org/pdb/home/home.do. Accessed Sep 23, 2013.

15. Okuno Y, Tanaka K, Baba K, Maeda A, Kunita N, Ueda S. Rapid focus reduction neutralization test of influenza $\mathrm{A}$ and $\mathrm{B}$ viruses in microtiter system. J Clin Microbiol. 1990;28(6):1308-1313.

16. National Research Council. Guide for the Care and Use of Laboratory Animals. Washington DC: National Academic Press; 1996.

17. Niederhäuser S, Bruegger D, Zahno ML, et al. A synthetic peptide encompassing the G5 antigenic region of the rabies virus induces high avidity but poorly neutralizing antibody in immunized animals. Vaccine. 2008;26(52):6749-6753.

18. Inoue $\mathrm{Y}$, Kubota-Koketsu R, Yamashita A, et al. Induction of antiinfluenza immunity by modified green fluorescent protein (GFP) carrying hemagglutinin-derived epitope structure. J Biol Chem. 2013;288(7):4981-4990.

19. Sidwell RW, Smee DF. In vitro and in vivo assay systems for study of influenza virus inhibitors. Antiviral Res. 2000;48(1):1-16.
Biologics: Targets \& Therapy

\section{Publish your work in this journal}

Biologics: Targets \& Therapy is an international, peer-reviewed journa focusing on the patho-physiological rationale for and clinical application of Biologic agents in the management of autoimmune diseases, cancers or other pathologies where a molecular target can be identified. This journal is indexed on PubMed Central, CAS, EMBase, Scopus

\section{Dovepress}

and the Elsevier Bibliographic databases. The manuscript management system is completely online and includes a very quick and fair peerreview system, which is all easy to use. Visit http://www.dovepress. com/testimonials.php to read real quotes from published authors. 